\title{
Papers
}

\section{Role of mobile phones in motor vehicle crashes resulting in hospital attendance: a case-crossover study}

\author{
Suzanne P McEvoy, Mark R Stevenson, Anne T McCartt, Mark Woodward, Claire Haworth, Peter Palamara,
} Rina Cercarelli

\begin{abstract}
Objectives To explore the effect of drivers' use of mobile (cell) phones on road safety.

Design A case-crossover study.

Setting Perth, Western Australia.

Participants 456 drivers aged $\geq 17$ years who owned or used mobile phones and had been involved in road crashes necessitating hospital attendance between April 2002 and July 2004.

Main outcome measure Driver's use of mobile phone at estimated time of crash and on trips at the same time of day in the week before the crash. Interviews with drivers in hospital and phone company's records of phone use.

Results Driver's use of a mobile phone up to 10 minutes before a crash was associated with a fourfold increased likelihood of crashing (odds ratio 4.1, 95\% confidence interval 2.2 to 7.7 , $\mathrm{P}<0.001)$. Risk was raised irrespective of whether or not a hands-free device was used (hands-free: 3.8, 1.8 to 8.0, $\mathrm{P}<0.001$; hand held: 4.9, 1.6 to $15.5, \mathrm{P}=0.003$ ). Increased risk was similar in men and women and in drivers aged $\geq 30$ and $<30$ years. A third $(n=21)$ of calls before crashes and on trips during the previous week were reportedly on hand held phones.

Conclusions When drivers use a mobile phone there is an increased likelihood of a crash resulting in injury. Using a hands-free phone is not any safer.
\end{abstract}

\section{Introduction}

Surveys indicate that drivers often talk on mobile (cell) phones. A 2004 observational survey of drivers of passenger vehicles in the United States indicated that at any given time of day $5 \%$ were talking on hand held phones. ${ }^{1}$ Observational studies in other countries have reported lower rates of use..$^{2-4}$ Internationally, drivers report usually using hand held phones. ${ }^{5-7}$ Because of concerns about risks of a potential crash, use of hand held phones is illegal in most countries in the European Union, all Australian states, the Canadian province of Newfoundland and Labrador, and New York, New Jersey, and the District of Columbia in the United States.

Most research on the safety implications of drivers' use of mobile phones has been experimental in design, involving small samples of volunteers. These studies have found that phone use impairs performance on simulated or instrumented driving tasks, using such measures as reaction time, ${ }^{8-11}$ variability of lane position and speed, ${ }^{10}$ following distance, ${ }^{11}$ and situational awareness. ${ }^{9}{ }^{12}$ Impairments have resulted from cognitive distractions whether drivers are using either hands-free ${ }^{89}$ or hand held ${ }^{13} 14$ phones. Studies also have reported effects of physical distraction from handling phones. ${ }^{15}{ }^{16}$ It is unknown whether experimental findings are applicable to drivers using phones in their own vehicles.

A few epidemiological studies have assessed the risk of crashes associated with phone use. Police crash reports are not useful in this regard because information on the driver's phone use is unreliable. Two studies found modest increases in risk among drivers observed using hand held phones ${ }^{17}$ and among more frequent versus less frequent users according to billing records from mobile phone companies. ${ }^{7}$ Neither study examined phone use at the time of the crash. Using billing records to verify phone use by drivers involved in crashes that involved damage to property, Redelmeier and Tibshirani ${ }^{18}$ compared phone use immediately before the crash with use during the previous week. The estimated risk of a crash while using phones was four times higher than when phones were not used. Hands-free phones seemed to offer no safety advantage over hand held phones, though few drivers had hands-free phones.

Important questions remain about the effects of phone use on the risk of a crash. These include whether use affects the risk of more serious crashes involving personal injuries and whether the risk differs for hands-free versus hand held phones. We studied drivers involved in injury crashes in Perth, Western Australia, where mobile phone company records could be obtained. Since 1 July 2001 it has been illegal to use a hand held phone when driving in Western Australia.

\section{Methods}

We used a case-crossover design, a variation of a case-control design that is appropriate when a brief exposure (driver's phone use) causes a transient rise in the risk of a rare outcome (a crash). We compared a driver's use of a mobile phone at the estimated time of a crash with the same driver's use during another suitable time period. Because drivers are their own controls, the design controls for characteristics of the driver that may affect the risk of a crash but do not change over a short period of time. As it is important that risks during control periods and crash trips are similar, we compared phone activity during the hazard interval (time immediately before the crash) with phone activity during control intervals (equivalent times during which participants were driving but did not crash) in the previous week.

\section{Study setting and participants}

Participants were consenting drivers aged $\geqslant 17$ years who were involved in a crash between April 2002 and July 2004, were seen 
in one of three main hospital emergency departments in the metropolitan area, and reported owning or using a mobile phone. Research officers recruited drivers in emergency departments from Monday to Friday between 8 am and $9 \mathrm{pm}$. We also included the few people who were admitted to hospital or remained in the emergency department after a weekend or overnight crash. We excluded motorcyclists and cyclists, those who sustained moderate or serious head injuries, those involved in crashes involving a fatality, and those with poor English. Drivers who were taken to hospital by ambulance were identified by using a real time automatic text messaging service from the sole road transport ambulance provider. Those who were transported by other means were identified through contact three times a day with hospitals during recruitment hours.

\section{Data collection}

We interviewed drivers after medical or nursing staff permitted access and collected data on demographics, usual patterns of driving and mobile phone use, description of crash and preceding events (including phone use), and type of phone. We sought additional information regarding crashes and injuries from medical records. We accessed records of participants' mobile phone use for two hours before and after the crash as well as for the same time window during three control periods (24 hours, 72 hours, and 7 days before the crash). Phone activity was defined as calls made or received and text messages sent. Voice mail and text messages received were excluded unless drivers confirmed that they checked these while they were driving. Drivers reported what type of phone they used. If there was a handsfree device in the vehicle, irrespective of its use during the hazard and control periods, this was considered as hands-free phone use. Drivers were not asked what type of phone they used during the crash trip because of concerns about the veracity of responses and hospital concerns about legal issues because at the time it was illegal to use hand held phones while driving.

The three major telecommunication networks (Optus, Telstra, and Vodafone) provided records of relevant phone activity for consenting participants.

\section{Time of crash}

Time of crash was estimated from several sources, including emergency response records, medical records, and self report from drivers interviewed in hospital; the latter sometimes included a review of call records stored on the drivers' phones. For most cases, we used the earliest reported time to reduce the misclassification of calls made after the crash as occurring before. We also compared data from the phone company with self reported data. In the event of discrepancies, we followed up participants by telephone and re-checked mobile phone data. If a participant reported a single call after the crash and mobile phone data recorded a single call that seemed to have been placed just before the crash, we assumed that the crash time was imprecise and the call was classified as after the crash. Thus, if this procedure biased the results, it would be expected to favour the null hypothesis that phone use was not associated with risk of crash.

\section{Hazard and control intervals}

The hazard interval was defined as the 10 minute period before the crash. For drivers who had driven for less than 10 minutes when a crash occurred, we considered only the phone activity while the participant was driving on the assumption that activity before driving would not have influenced risk of a crash. We compared phone activity during a hazard interval with activity during control interval(s) of the same time and duration 24 hours, 72 hours, and 7 days before the crash when drivers confirmed, during the interview, that they had been driving. We analysed a hazard or control interval of up to 5 minutes to test the robustness of the results.

\section{Statistical analysis}

Before the study started, we estimated the sample size using prevalence data from an observational survey. ${ }^{2}$ We conducted matched analyses using conditional logistic regression to calculate the odds of having an injury crash in association with mobile phone use. ${ }^{19}$ The primary analysis involved 1:multiple $(1: \mathrm{M})$ matching $^{20}$ : phone use during the hazard interval for any driver was compared with between one and three control intervals depending on whether the driver reported driving during those control intervals. We excluded participants who denied driving during any control interval. Paired analyses were conducted as sensitivity analyses; a hazard interval was compared with a single control interval (24 hours, 72 hours, or 7 days) according to a participant's reported driving during each interval. We calculated odds ratios, $95 \%$ confidence intervals, and $\mathrm{P}$ values with Stata version 8 (StataCorp, College Station, TX). Subgroup analyses based on sex, age group, and phone type (hand held or hands-free) used 1:M matching. Odds ratios for subgroups were compared with a $\chi^{2}$ test with one degree of freedom.

\section{Results}

Of 1625 drivers approached, 454 (28\%) did not own or use mobile phones, $133(8 \%)$ met another exclusion criterion, and 97 $(6 \%)$ declined participation. The $941(58 \%)$ remaining drivers were interviewed, and mobile phone activity records of 744 $(79 \%)$ were available. Reasons for non-availability of records included refusal to allow access $(\mathrm{n}=70)$, use of company phones $(\mathrm{n}=47)$, phone data not accessible $(\mathrm{n}=35)$, other owner $(\mathrm{n}=24)$, and inability to recall phone number $(n=21)$. Among drivers with available phone records, $456(61 \%)$ verified driving during at least one control interval. These were the study subjects and the basis of the case-crossover analyses. Tables 1 and 2 summarise characteristics of drivers and crashes for drivers who completed interviews, interviewed drivers with available phone records, and the case-crossover drivers.

Most participants $(\mathrm{n}=423,93 \%)$ had at least one injury and $44 \%(\mathrm{n}=201)$ had two or more. Injuries included sprains and strains $(\mathrm{n}=252,55 \%)$, haematomas and bruising $(\mathrm{n}=149,33 \%)$, abrasions and lacerations $(\mathrm{n}=94,21 \%)$, fractures and dislocations $(\mathrm{n}=65,14 \%)$, minor head injuries $(\mathrm{n}=35,8 \%)$, internal organ injuries to chest or abdomen $(n=14,3 \%)$, and spinal injuries $(\mathrm{n}=8,2 \%)$. Injuries were predominantly mild to moderate in severity.

Despite owning or using mobile phones, 28\% $(n=126)$ of participants said they never used the phone while driving. Of those $(72 \%)$ who reported using a phone while driving, the proportion with hands-free devices ranged from $60 \%(\mathrm{n}=134)$ for those who occasionally used a phone while driving to $82 \%$ $(\mathrm{n}=37)$ for those who often did.

In total, about half the participants $(\mathrm{n}=238,52 \%)$ reported having hands-free devices in their vehicles, including earpieces $(\mathrm{n}=164,36 \%)$, fully installed hands-free car kits $(\mathrm{n}=45,10 \%)$, headsets $(n=20,4 \%)$, and speaker phones on handsets $(n=9$, $2 \%$; table 1$)$. Only $6 \%(\mathrm{n}=29)$ had phones with voice activation features. Thirty drivers with a hands-free device in their vehicles (13\%) said they never used a phone while driving; 159 (67\%) reported using the hands-free device for phone activity when driving at least $90 \%$ of the time; and only 21 (9\%) reported using 
Table 1 Characteristics of drivers based on interview. Figures are numbers (percentages) of participants

\begin{tabular}{|c|c|c|c|}
\hline & $\begin{array}{l}\text { Drivers interviewed } \\
\qquad(\mathrm{n}=941)\end{array}$ & $\begin{array}{l}\text { Drivers with phone } \\
\text { activity records } \\
(n=744)\end{array}$ & $\begin{array}{c}\text { Drivers in } \\
\text { case-crossover } \\
\text { analysis* }(n=456)\end{array}$ \\
\hline Men & $441(46.9)$ & $335(45.0)$ & $192(42.1)$ \\
\hline \multicolumn{4}{|l|}{ Age (years): } \\
\hline $17-29$ & $443(47.1)$ & $356(47.8)$ & $220(48.2)$ \\
\hline $30-49$ & $340(36.1)$ & $277(37.2)$ & $169(37.1)$ \\
\hline$>50$ & $158(16.8)$ & $111(15.0)$ & $67(14.7)$ \\
\hline \multicolumn{4}{|c|}{ Driving experience (years): } \\
\hline $0-9$ & $438(46.5)$ & $350(47.0)$ & 217 (47.6) \\
\hline $10-19$ & $199(21.1)$ & $167(22.4)$ & $100(21.9)$ \\
\hline $20-29$ & $145(15.4)$ & 111 (14.9) & $71(15.6)$ \\
\hline$\geq 30$ & $159(16.9)$ & $116(15.6)$ & $68(14.9)$ \\
\hline \multicolumn{4}{|c|}{ Type of mobile phone in vehicle: } \\
\hline Hand held & $475(50.5)$ & $373(50.1)$ & $218(47.8)$ \\
\hline $\begin{array}{l}\text { Fully installed } \\
\text { hands-free kit }\end{array}$ & $103(10.9)$ & $77(10.3)$ & $45(9.9)$ \\
\hline Earpiece & $314(33.4)$ & $250(33.6)$ & $164(35.9)$ \\
\hline Headset & $35(3.7)$ & $32(4.3)$ & $20(4.4)$ \\
\hline $\begin{array}{l}\text { Speaker phone on } \\
\text { handset }\end{array}$ & $12(1.3)$ & $11(1.5)$ & $9(2.0)$ \\
\hline $\begin{array}{l}\text { Other hands-free } \\
\text { device }\end{array}$ & $2(0.2)$ & $1(0.1)$ & - \\
\hline \multicolumn{4}{|c|}{ Mobile phone use while driving: } \\
\hline Never use & $296(31.5)$ & $229(30.8)$ & $126(27.6)$ \\
\hline Occasionally use & $425(45.2)$ & $352(47.3)$ & $225(49.3)$ \\
\hline Sometimes use & $135(14.3)$ & $94(12.6)$ & $60(13.2)$ \\
\hline Frequently use & $85(9.0)$ & $69(9.3)$ & $45(9.9)$ \\
\hline Carrying phone on trip & 827 (87.9) & $666(89.5)$ & 411 (90.1) \\
\hline $\begin{array}{l}\text { Reported using } \\
\text { phone before crash }\end{array}$ & $72(7.7)$ & $62(8.3)$ & $32(7.0)$ \\
\hline $\begin{array}{l}\text { Reported using } \\
\text { phone after crash }\end{array}$ & 432 (45.9) & $358(48.1)$ & $234(51.3)$ \\
\hline $\begin{array}{l}\text { Regular weekly } \\
\text { driving pattern }\end{array}$ & 678 (72.1) & 550 (73.9) & $362(79.4)$ \\
\hline $\begin{array}{l}\text { Automatic transmission } \\
\text { in vehicle }\end{array}$ & $471 \quad(50.1)$ & $381 \quad(51.2)$ & $228(50.0)$ \\
\hline
\end{tabular}

${ }^{*}$ Those with available records on mobile phone activity who reported driving during at least one control interval.

it less than half the time. Thus, of drivers who had hands-free devices and reported using a phone while driving, almost all said they generally used these devices.

Most drivers $(\mathrm{n}=411,90 \%)$ were carrying their mobile phones during the crash trips (table 1$)$, and $7 \%(\mathrm{n}=32)$ said they used the phone sometime during that trip. About half $(n=234$, $51 \%$ ) reportedly used their phones at least once after crashing, most commonly to contact family members $(n=152,65 \%)$, friends $(\mathrm{n}=53,23 \%)$, workplace $(\mathrm{n}=42,18 \%)$, and emergency services $(n=31,13 \%)$.

Of the 456 participants, 192 (42\%) had driven during one control interval, $183(40 \%)$ had driven during two, and $81(18 \%)$ had driven during all three. This resulted in 456 case intervals and 801 control intervals available for analysis with multiple control periods. Phone records indicated that 40 of the 456 subjects $(9 \%)$ used mobile phones during the hazard interval (that is, up to 10 minutes before the crash). Phones were used during 3\% $(n=25)$ of the 801 multiple control intervals. Based on the reported availability of hands-free devices, about one third $(n=13)$ of calls during the hazard interval and one third $(n=8)$ of calls during control intervals were on hand held phones. Of drivers with hands-free devices who used their phones during the hazard interval, $89 \%(\mathrm{n}=24)$ reported that they used their hands-free devices for phone activity when driving at least $90 \%$ of the time.
Table 2 Characteristics of crashes. Figures are numbers (percentages) of participants

\begin{tabular}{|c|c|c|c|}
\hline & $\begin{array}{l}\text { Drivers interviewed } \\
\qquad(\mathrm{n}=941)\end{array}$ & $\begin{array}{l}\text { Drivers with phone } \\
\text { activity records } \\
\quad(n=744)\end{array}$ & $\begin{array}{c}\text { Drivers in } \\
\text { case-crossover } \\
\text { analysis* }(n=456)\end{array}$ \\
\hline \multicolumn{4}{|l|}{ Day of crash: } \\
\hline Monday & $154(16.4)$ & $124(16.7)$ & $73(16.0)$ \\
\hline Tuesday & $188(20.0)$ & $142(19.1)$ & 101 \\
\hline Wednesday & $174(18.5)$ & $136(18.3)$ & $86(18.9)$ \\
\hline Thursday & $174(18.5)$ & $149(20.0)$ & $94(20.6)$ \\
\hline Friday & $187(19.9)$ & $145(19.5)$ & $80(17.5)$ \\
\hline Saturday & $34(3.6)$ & $24(3.2)$ & $9(2.0)$ \\
\hline Sunday & $30(3.2)$ & $24(3.2)$ & $13(2.9)$ \\
\hline \multicolumn{4}{|c|}{ Time of crash (24 hour clock): } \\
\hline $\begin{array}{l}0500-0959 \\
\end{array}$ & $251(26.7)$ & $202(27.2)$ & $150(32.9)$ \\
\hline $1000-1459$ & $283(30.1)$ & $212(28.5)$ & $122(26.8)$ \\
\hline 1500-1959 & $346(36.8)$ & $281(37.8)$ & $165(36.2)$ \\
\hline $2000-0459$ & $61(6.5)$ & $49(6.6)$ & $19(4.2)$ \\
\hline \multicolumn{4}{|l|}{ Weather conditions: } \\
\hline Fine & 686 (72.9) & 539 (72.4) & $330(72.4)$ \\
\hline Overcast & $147(15.6)$ & $121(16.3)$ & $81(17.8)$ \\
\hline Rain & $108(11.5)$ & $84(11.3)$ & $45(9.9)$ \\
\hline \multicolumn{4}{|c|}{ Trip length before crash (mins): } \\
\hline$\leq 10$ & $593(63.0)$ & $479(64.4)$ & $288(63.2)$ \\
\hline $11-60$ & $318(33.8)$ & $244(32.8)$ & $159(34.9)$ \\
\hline$>60$ & $26(2.8)$ & $17(2.3)$ & $8(1.8)$ \\
\hline Unknown & $4(0.4)$ & $4(0.5)$ & $1(0.2)$ \\
\hline \multicolumn{4}{|l|}{ Vehicles involved: } \\
\hline Single & 139 (14.8) & $108(14.5)$ & $49(10.7)$ \\
\hline Multiple & $802(85.2)$ & $636(85.5)$ & 407 (89.3) \\
\hline \multicolumn{4}{|c|}{ Site of crash impact: } \\
\hline Rear end & $141(15.0)$ & $112(15.1)$ & $73(16.0)$ \\
\hline Front end & 504 (53.6) & $400(53.8)$ & $247(54.2)$ \\
\hline Side impact & $104(11.1)$ & $85(11.4)$ & $46(10.1)$ \\
\hline Multiple impact & $112(11.9)$ & $90(12.1)$ & $63(13.8)$ \\
\hline Rollover, other & $45(4.8)$ & $35(4.7)$ & $17(3.7)$ \\
\hline Unknown & $35(3.7)$ & $22(3.0)$ & $10(2.2)$ \\
\hline \multicolumn{4}{|l|}{ Driver factors: } \\
\hline Speed $\dagger$ & $155(16.5)$ & $121(16.3)$ & $64(14.0)$ \\
\hline Alcohol & $44(4.7)$ & $36(4.8)$ & $13(2.9)$ \\
\hline Drugs & $19(2.0)$ & $15(2.0)$ & $10(2.2)$ \\
\hline Fatigue & $30(3.2)$ & $24(3.2)$ & $15(3.3)$ \\
\hline
\end{tabular}

${ }^{*}$ Those with available mobile phone activity records who reported driving during at least one control interval.

†Defined as factor if at least one vehicle was reportedly exceeding posted speed limit.

Mobile phone use within the period during and up to 10 minutes before the estimated time of the crash was associated with a fourfold increase in the likelihood of crashing (odds ratio $4.1,95 \%$ confidence interval 2.2 to $7.7, \mathrm{P}<0.001$ ) (table 3 ). Similar results were obtained when we analysed only the interval up to 5 minutes before a crash $(3.6,1.8$ to $7.0, \mathrm{P}<0.001)$. Analyses with paired matching to compare the hazard interval with an equivalent single control interval also showed significant associations between mobile phone use and the likelihood of a crash, similar in magnitude to the association with 1:M matching (table 3).

Sex, age group, or type of mobile phone did not affect the association between phone use and risk of crash $(\mathrm{P}>0.05)$ (table 4). In particular, both hand held and hands-free phone use while driving was associated with increased risk $(4.9,1.6$ to 15.5 , $\mathrm{P}=0.003$ v 3.8, 1.8 to $8.0, \mathrm{P}<0.001$, respectively).

\section{Discussion}

A person using a mobile phone when driving is four times more likely to have a crash that will result in hospital attendance. Sex, 
Table 3 Risk of injury crash and use of mobile phone while driving

\begin{tabular}{|c|c|c|c|c|c|}
\hline \multirow[b]{2}{*}{ Type of matching } & \multicolumn{2}{|c|}{ Hazard interval (up to 10 minutes before crash) } & \multicolumn{2}{|c|}{ Control driving interval(s) } & \multirow[b]{2}{*}{ Odds ratio $(95 \% \mathrm{Cl})$} \\
\hline & Drivers using phones & All drivers & Drivers using phones & Total & \\
\hline 1:M (multiple control intervals) & 40 & 456 & 25 & 801 & 4.1 (2.2 to 7.7$)$ \\
\hline 1:1 (24 hours before crash) & 26 & 248 & 10 & 248 & 3.7 (1.5 to 9.0$)$ \\
\hline 1:1 (72 hours before crash) & 15 & 227 & 4 & 227 & 4.7 (1.3 to 16.2$)$ \\
\hline 1:1 (7 days before crash) & 32 & 326 & 11 & 326 & $4.5(1.9$ to 10.9$)$ \\
\hline
\end{tabular}

age group, or availability of a hands-free device do not influence the increased likelihood of a crash. In this study, we measured the seriousness of crashes by participants' injuries; almost all had at least one injury and almost half had two or more.

\section{Comparison with other research}

Some authors have suggested that drivers who use mobile phones while driving may inherently take more risks than other drivers. ${ }^{17}$ This may be true, but the case-crossover design of this study controlled for risk taking and other characteristics of drivers that may affect risk but do not change over a short period of time.

Our findings are similar to those reported by Redelmeier and Tibshirani, whose case-crossover study found a fourfold increased risk of crashes that result in damage to property associated with phone use. ${ }^{18}$ These similar findings occurred despite some notable differences in the methods of the studies. In our study we collected and reconciled, where possible, both drivers' reports of phone use before crashes and data from phone companies. Because of the higher proportion of drivers with handsfree devices in our study, we were able to estimate the risk of crashes associated with hands-free and hand held phones. We assumed that phone use could have influenced risk of crash only when participants were driving, and participants included only those drivers who reported in their initial interviews that they had been driving during at least one control interval. Redelmeier and Tibshirani did not initially collect information on driving during control intervals. ${ }^{18}$ They adjusted estimates of risk based on information from a separate pilot study and from interviews with a small subset of participants conducted a year after the crash. Some researchers questioned whether these adjustments adequately addressed the issue. ${ }^{21}{ }^{22}$ While our approach did not remove the potential for recall bias, it probably reduced it. The lengths of hazard and corresponding control intervals in our study were not fixed, as used by Redelmeier and Tibshirani ${ }^{18}$ but varied up to 10 minutes according to the duration of the driving trip in which a crash occurred. As $63 \%(\mathrm{n}=288)$ of drivers reported a trip length of 10 minutes or less before crashing this could have been an important consideration.

\section{Limitations}

The precise time of the crash may not be known with absolute certainty, and the possibility of misclassifying calls after the crash as those before the crash was a concern. We minimised misclassi- fication bias by subsequent verification of self report and mobile phone records when these sources differed. This did not eliminate the possibility that for legal or social reasons participants said they had not used the phone before crashing. The overall effect of non-reporting would have been to bias the result toward the null hypothesis, thereby underestimating the risk of phone use. Participation rates were high, and we did not identify important differences among drivers who were interviewed, drivers whose phone records were obtained, and study participants. However, it is possible that drivers who refused to take part or refused access to phone records differed from our remaining participants. Again, the overall effect would have been to bias the result toward the null hypothesis.

We took care to verify that participants were driving during the hazard and control intervals, but circumstances of the control driving intervals may have differed from the crash driving interval, and the findings point to a statistical rather than causal association. Our results, however, reflect those reported by Redelmeier and Tibshirani, ${ }^{18}$ as well as those from the numerous experimental studies. ${ }^{8-12}$

The distracting effects of different types of hands-free phones may not be equivalent-for example, searching for an earpiece to answer an incoming call may be more distracting than answering a phone mounted in a hands-free kit. Although voice activated units are becoming more common, only $6 \%$ of mobile phone users in our study had phones with this feature. The sample size was not large enough to assess whether certain types of hands-free devices, including fully hands-free, might be safer than other types.

\section{Policy implications}

Mobile phone use while driving may result in physical or cognitive distraction. In an effort to minimise the effects of handling phones, many jurisdictions, including Western Australia, have laws prohibiting the use of hand held phones while driving. Although not based on rigorous sampling methods, periodic roadside observations conducted in Perth before, during, and after our study indicated that about $2 \%$ of drivers were illegally using hand held phones. Furthermore, $37 \%(n=122)$ of participants who reported using phones while driving, at least on occasion, reported not having a hands-free device in their vehicle.

Studies of laws prohibiting use of hand held phones in the US found that such use declined significantly in the first few

Table 4 Risk of injury crash and mobile phone use, using multiple control intervals, by sex, age group, and hands-free and hand held phones

\begin{tabular}{|c|c|c|c|c|c|}
\hline & \multicolumn{2}{|c|}{ Hazard interval (10 minutes before crash) } & \multicolumn{2}{|c|}{ Control driving interval(s) } & \multirow[b]{2}{*}{ Odds ratio $(95 \% \mathrm{Cl})$} \\
\hline & Drivers using phones & All drivers & Drivers using phones & Total & \\
\hline Men & 19 & 192 & 13 & 352 & $5.2(1.9$ to 14.4$)$ \\
\hline Women & 21 & 264 & 12 & 449 & 3.5 (1.6 to 7.7$)$ \\
\hline \multicolumn{6}{|c|}{ Age group (years): } \\
\hline$<30$ & 19 & 220 & 12 & 373 & $3.9(1.6$ to 9.4$)$ \\
\hline$\geq 30$ & 21 & 236 & 13 & 428 & 4.3 (1.8 to 10.5$)$ \\
\hline \multicolumn{6}{|c|}{ Type of mobile phone: } \\
\hline Hand held & 13 & 218 & 8 & 377 & 4.9 (1.6 to 15.5$)$ \\
\hline Hands-free & 27 & 238 & 17 & 424 & 3.8 (1.8 to 8.0$)$ \\
\hline
\end{tabular}




\section{What is already known on this topic}

Many drivers use mobile phones while driving and laboratory based research has highlighted that this impairs driving performance

Epidemiological research has shown an association between phone use and increased risk of crashes that result in property damage

\section{What this paper adds}

Use of mobile phones is associated with an increased likelihood of serious road crashes resulting in hospital attendance

The use of currently available hands-free devices does not seem to reduce the risk

months after the laws took effect. ${ }^{23}{ }^{24}$ In New York, use of hand held phones subsequently returned to levels seen before the law. Publicised enforcement campaigns may be needed to achieve long term compliance. Even full compliance, however, will not eliminate the risk of crashes. According to our study, there is no safety advantage associated with switching to the types of handsfree devices that are commonly in use.

Laws limiting all phone use while driving would be difficult to enforce. While a possible solution in the future is to change mobile phones so they cannot be used when vehicles are in motion, the likelihood the industry would embrace such a change seems remote. More and more new vehicles are being equipped with Bluetooth technology, facilitating voice activation and therefore totally hands-free phone use. Though this may lead to fewer hand held phones used while driving in the future, our research indicates that this may not remove the risk. Importantly, if this new technology actually increases mobile phone use in cars, it could contribute to even more crashes. At least in the short term, it seems likely that mobile phone use in cars will continue to grow, despite the growing evidence of the risk it creates.

We acknowledge the contributions of Margaret Hocking, Peter McEvoy, and Cheri Donaldson. We also thank the participating hospitals (Fremantle, Royal Perth, and Sir Charles Gairdner), St John Ambulance Service, and Optus, Telstra, and Vodafone.

Contributors: SPM and MRS contributed to study design, conduct, analysis, and writing of the manuscript. ATM contributed to study design, analysis, and writing of the manuscript. MW contributed to study analysis and writing of the manuscript. CH, PP, and RC contributed to study design and conduct. MRS is guarantor.

Funding: Insurance Institute for Highway Safety. SPM received a National Health and Medical Research Council postgraduate public health scholarship.

Competing interests: None declared.
Ethical approval: Human research ethics committees at the University of Western Australia and the participating hospitals approved the study.

1 Glassbrenner D. Driver cell phone use in 2004, overall results. Washington, DC: US National Highway Traffic Safety Administration, 2005. (DOT HS-809-847.)

2 Horberry T, Bubnich C, Hartleyk L, Lamble D. Drivers' use of hand-held mobile phones in Western Australia. Transportation Research Part F 2001;4:213-8.

3 Johal S, Napier F, Britt-Compton J, Marshall T. Mobile phones and driving. J Public Health Oxf 2005;27:112-3.

4 Taylor DMcD, Bennett DM, Carter M, Garewal D. Mobile telephone use among Melbourne drivers: a preventable exposure to injury risk. Med J Aust 2003;179:140-2.

5 Royal D. National survey of distracted and drowsy driving attitudes and behaviour: 2002. Vol 1. Findings. Washington, DC: National Highway Traffic Safety Administration, 2003. (DOT HS-809-566.)

6 Sullman MJM, Baas PH. Mobile phone use amongst New Zealand drivers. Transportation Research Part $F$ 2004;7:95-105.

7 Laberge-Nadeau C, Maag U, Bellavance F, Lesjardins D, Messier S, et al. Wireless telephones and the risk of road crashes. Accid Anal Prev 2003;35:649-60.

8 Consiglio W, Driscoll P, Witte M, Berg WP. Effect of cellular telephone conversations and other potential interference on reaction time in a braking response. Accid Anal Prev 2003;35:495-500.

9 Strayer DL, Drews FA, Johnston WA. Cell phone-induced failures of visual attention during simulated driving. J Exp Psychol Appl 2003;9:23-32.

$10 \mathrm{Alm} \mathrm{H}$, Nilsson L. Changes in driver behaviour as a function of hands free mobile phones-a simulator study. Accid Anal Prev 1994;26:441-51.

11 Alm H, Nilsson L. The effects of a mobile telephone task on driver behaviour in a car Alm H, Nilsson L. The effects of a mobile telephon
following situation. Accid Anal Prev 1995;27:707-15.

12 McKnight AJ, McKnight AS. The effect of cellular phone use upon driver attention. Accid Anal Prev 1993;25:259-65.

13 Accid Anal Prev 1993;25:259-65. driving performance: task demand characteristics and compensatory process. Transportation Research Part F 2000;3:113-21.

14 Matthews R, Legg S, Charlton S. The effect of cell phone type on drivers' subjective workload during concurrent driving and conversing. Accid Anal Prev 2003;35:451-7.

15 Brookhuis KA, DeVries G, DeWaard D. The effects of mobile telephoning on driver performance. Accid Anal Prev 1991;23:309-16.

16 Wikman A-S, Nieminen T, Summala H. Driving experience and time-sharing during in-car tasks on roads of different width. Ergonomics 1998;41:358-72.

17 Wilson J, Fang M, Wiggins S. Collision and violation involvement of drivers who use Wilson J, Fang M, Wiggins S. Collision and vio

18 Redelmeier DA, Tibshirani RJ. Association between cellular telephone calls and motor vehicle collisions. N Engl J Med 1997;336:453-8.

19 Woodward M. Epidemiology: study design and data analysis. 2nd ed. Boca Raton, FL. Chapman and Hall/CRC Press, 2005.

20 Mittleman MA, Maclure M, Robins JM. Control sampling strategies for case-crossover studies: an assessment of relative efficiency. Am J Epidemiol 1995;142:91-8.

21 Maclure M, Mittleman MA. Cautions about car telephones and collisions. N Engl J Med 1997;336:501-2.

22 Goodman MJ, Tijerina L, Bents FD, Wierwille W. Using cellular telephones in vehicles: safe or unsafe? Transportation Human Factors 1999;1:3-42.

23 McCartt AT, Geary LL. Longer term effects of New York State's law on drivers' handheld cell phone use. Inj Prev 2004;10:11-5.

24 McCartt AT, Hellinga LA, Geary LL. Effects of Washington, DC, law on drivers' hand-held cell phone use. Arlington, VA: Insurance Institute for Highway Safety, 2005. (Accepted 24 June 2005)

doi $10.1136 /$ bmj. 38537.397512 .55

The George Institute for International Health, University of Sydney, PO Box M201, Sydney, NSW 2050, Australia

Suzanne P McEvoy senior research fellow

Mark R Stevenson professor of injury prevention

Mark Woodward professor of biostatistics

Insurance Institute for Highway Safety, Arlington, VA, USA

Anne T McCartt vice president, research

Injury Research Centre, University of Western Australia, Crawley, WA 6009,

Australia

Claire Haworth research nurse

Peter Palamara senior research officer

Rina Cercarelli senior research fellow

Correspondence to: S McEvoy smcevoy@thegeorgeinstitute.org 